\title{
Fuzzy Fragility Analysis of Structures with Masonry Infill Walls
}

Open Access

\author{
Nikos D. Lagaros* \\ Institute of Structural Analysis \& Seismic Research, School of Civil Engineering, National Technical University Athens, \\ Zografou Campus, Athens 157 80, Greece
}

\begin{abstract}
In this work fragility analysis of reinforced concrete and steel structures withinfill walls is performed.For this purpose a fuzzy-based fragility assessment framework for evaluating 3D framed structures is proposed taking into account various sources of uncertainty. In particular, randomness on the material properties and on the seismic demand is considered. The proposed framework requires the development of a fuzzy nonlinear static analysis model in order to define the limit states. The fragility curves are expressed in the form of a two-parameter lognormal distribution.
\end{abstract}

Keywords: Fuzzy response, fragility analysis, fibre modelling, nonlinear static analysis, steel and reinforced concrete structures.

\section{INTRODUCTION}

Seismic fragility analysis provides a measure of the safety margin for the structural system, sincefragilities represent the probabilities of exceedance of limit-states as functions of earthquake ground motion intensity. Therefore, fragility analysisis considered as the main ingredient of the risk assessment procedure.In the past a number of studies on fragility analysis of structural systems have been published[15]. Real-world structures are characterized by imperfections while the material properties and the loading conditions are uncertain, which induce deviations from the nominal state assumed by the design codes. A deterministic representation of a design that ignores scatter of any kind of the parameters affecting its response is never materialized in an absolute way, due to unavoidable scattering of the values of its parameters. So far a number of researchers studied the effect of uncertainties in the context of fragility analysis; mainly in steel and RC structures [6-10].

Modelling uncertainty in engineeringproblems as random variables or random processes becomes problematic when uncertain data have additional uncertainty besides the property of randomness. Fuzzy randomness is a generalized uncertainty model to describe samples with uncertainty of the single sample element. The basic terms and definitions related to fuzzy randomness can be found in [11-13]. Recently, non-probabilistic approaches for numerical engineering problems with uncertain variables have been proposed $[14,15]$, such as convex models, fuzzy sets, random sets, possibility the oryand others. The main motivation for adopting nonprobabilistic approaches is the high sensitivity offailure reliability to the tails of probability distributionsof the random variables involved in the analysis [16]. Publications implementing fuzzy numbers in fragility analysis are limited

\footnotetext{
*Address correspondence to this author at the Institute of Structural Analysis \& Seismic Research, School of Civil Engineering, National Technical University Athens, Greece; Tel: (+30) 2107722625 ;

E-mail: nlagaros@central.ntua.gr
}

in particular, Huo and Hwang [17] presented an approach for seismic fragility analysis including fuzzy damage states where four fuzzy damage states were defined and their membership functions were established based on the available experimental data. $\mathrm{Gu}$ and $\mathrm{Lu}$ [18] presented a fuzzyrandom model for the performance reliability analysis of $\mathrm{RC}$ framed structures considering both structural and non structural-damages. The limit state for each performance level was defined as an interval of inter-storey drift ratiosconcerning, respectively, the non-structural and structural damage with a membership function, while there lative importance of the two aspects was reflected through the use of an appropriate cost function.

In the present paper, a fragility analysis procedure for reinforced concrete (RC) and steel structures is establishedin the framework of fuzzy number theory, where uncertainties on the material properties and the seismic loads follow the proposal presented in the work by Elishak off and Ferracuti [19] and they are definedthrough membership functions. Two performance limits (mathematically defined throughfailure boundaries) are defined for the structures. After performing operations between fuzzy numbers, membership function of the response characterized with the maximum interstorey drift is obtained. Two 3D structures are considered while randomness on seismic demandand the material properties are taken into account.

\section{FRAGILITY ANALYSIS}

Earthquake risk assessment of building structures requires the calculation of limit-state probabilities for a series of limit-states. The target is to obtain the limit-state probabilities of exceedance that serve as a hazard curve for structural damage. The mean annual frequency of maximum interstorey drift $\theta_{\max }$ exceeding a value $y$ is obtained as:

$v_{\theta>y}=\int P\left(\theta_{\max } \geq y / I M=x\right)\left|d \lambda_{I M}(x)\right|$

where $v_{\theta>y}$ is the rate of $\theta_{\max }$ exceeding the value $y$ and $\lambda_{I M}(x)$ is the hazard curve representing the mean annual frequency 
of the chosen intensity measure exceeding $x$. The absolute value is used for the slope because it has a negative value.

According to equation (1) the seismic fragility $F_{R}$ is defined as the limit-state probability, conditioned on a measure of seismic intensity $I M$, which may be expressed as peak ground acceleration, spectral acceleration, spectral velocity, or any other control variable that is consistent with the specification of seismic hazard. In this work the first mode spectral acceleration $S_{A}\left(T_{1}, 5 \%\right)$ is used to represent the intensity of the seismic ground motion. Thus the seismic fragility curves are defined as:

$F_{R}=P\left(\theta_{\max } \geq y \mid I M=x\right)$

According to Shinozuka et al. [6] it is assumed that the curves $F_{R}$ can be expressed in the form of lognormal distribution function. Building fragility curves are lognormal functions that describe the probability of reaching or exceeding a specific limit state. The conditional probability of being in, or exceeding, a particular damage state $y$ given a peak ground acceleration, $P G A$, (or other seismic demand parameter) is defined by:

$F_{R, k}\left(\theta_{\max } \geq y \mid P G A\right)=\Phi\left[\frac{1}{\beta_{y}} \ln \left(\frac{P G A}{\mu_{P G A, y}}\right)\right]$

where $\mu_{P G A, y}$ is the median value of peak ground acceleration at which the building reaches the threshold of damage state, $y, \beta_{y}$ is the standard deviation of the natural logarithm of peak ground acceleration for the damage state $y$ and $\Phi$ is the standard normal cumulative distribution function.

\section{MODELLING AND FINITE ELEMENT ANALYSIS}

Nonlinear static or dynamic analysis needs a detailed simulation of the structure in the regions where inelastic deformations are expected to develop. In order to consider the inelastic behaviour either the plastic-hinge or the fibre approach can be adopted. For some researchers the plastic hinge approach has limitations in terms of accuracy and thereforefibre beam-column elements are preferred [20]. According to the fibre approach, each structural element is discretized into a number of integration sections restrained to the beam kinematics, and each section is divided into a number of fibres (Fig. 1) with specific material properties $\left(A_{f i b}\right.$, $\left.E_{f i b}\right)$. Everyfibre in the section can be assigned to different material properties, e.g. concrete, structural steel, or reinforcing bar material properties, whilethe sections are located at the Gaussian integration points of the elements.The main advantage of the fibre approach is that every fibre has a simple uniaxial material model allowing an easy and efficient implementation of the inelastic behaviour.In the numerical test examples section that follows, all analyses have been performed using the OpenSEES [21] platform. A bilinear material model with pure kinematic hardening is adopted for the structural steel, while geometric nonlinearity is explicitly taken into consideration. For the simulation of the concrete the modified Kent-Park model, where the monotonic envelope of concrete in compression follows the model of Kent and Park [22] as extended by Scott et al. in [23], is employed. This model was chosen because it allows for an accurate prediction of the demand for flexure-dominated RC members despite its relatively simple formulation. The transient behaviour of the reinforcing bars was simulated with the Menegotto-Pinto model [24].

In the work by Calvi et al. [25] a detailed parametric study is performed with respect to the parameters that affect the modelling of the infill walls while a detailed state-of-theart review on modelling approaches can be found in [26]. In this work the masonry infill walls are modelled by replacing their structural behaviour with a system of two equivalent diagonal compression struts [27, 28]. Figs. (2) and (3) depict the model and the strength envelope for masonry infill walls. The user defined parameters of the strength envelope model, described in Fig. (3), are the cracking shear $V_{y}$, the maximum strength $V_{m}$ and the post-peak residual shear strength $V_{p}$ together with the corresponding lateral displacement values, $u_{y}, u_{m}$ and $u_{p}$. The coefficient $\alpha$, is the ratio of stiffness after yielding to the initial stiffness. In order to define the parameters of the envelope curve, the maximum strength $V_{m}$ is first estimated considering the two critical failure modes, i.e. sliding shear and compression failures [28], while the remaining of the parameters are defined through the following expressions. The maximum strength is calculated based the formula given in the work by Dolšekand Fajfar [29]:

$$
V_{m}=0.818 \frac{l_{i n} t_{w} f_{t p}}{C_{I}}\left(1+\sqrt{C_{I}^{2}+1}\right) \quad C_{I}=1.925 \frac{l_{i n}}{h_{i n}}
$$

where $f_{t p}$ is the cracking strength of the infill (taken equal to $0.38 \mathrm{MPa}[30]), t_{w}$ is the infill wall thickness, $l_{i n}$ and $h_{i n}$ are

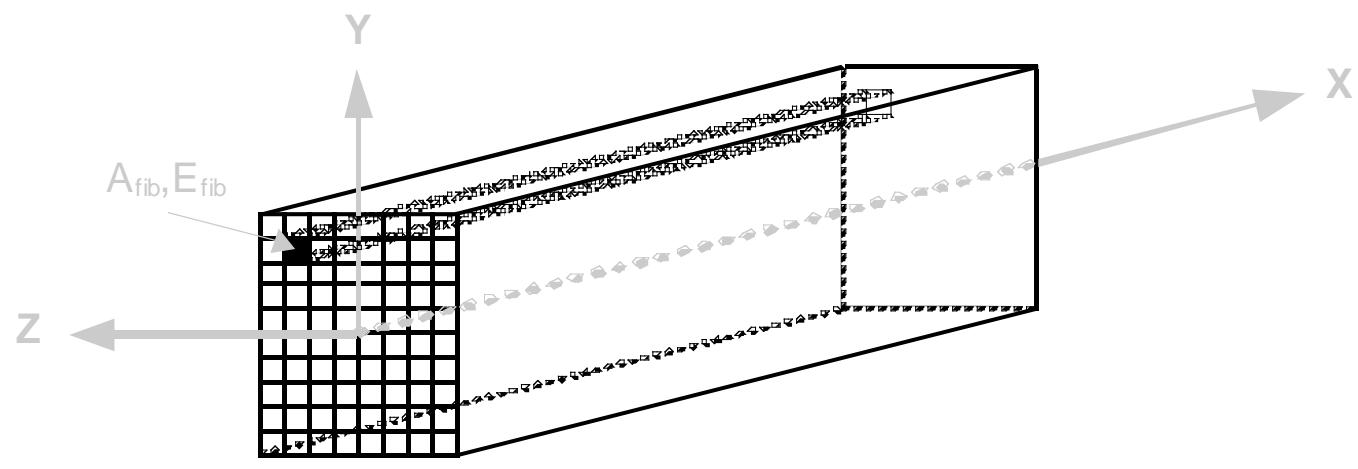

Fig. (1). Modelling of the inelastic behaviour with the fibre approach. 


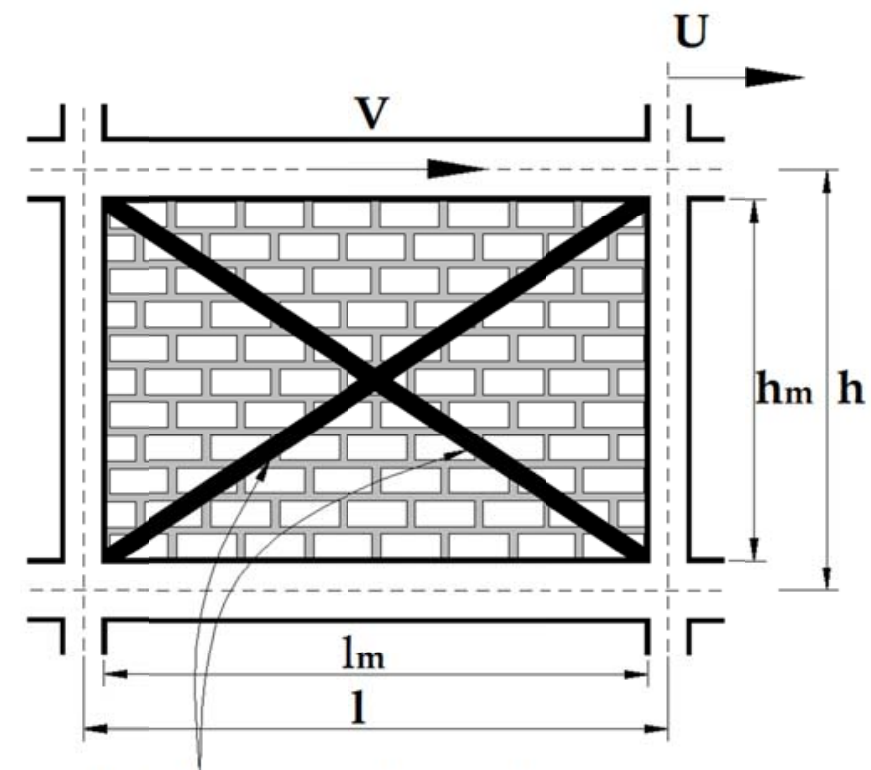

\section{Equivelant Diagonal Struts}

(only Compression Strength)

Fig. (2). The equivalent diagonal struts.

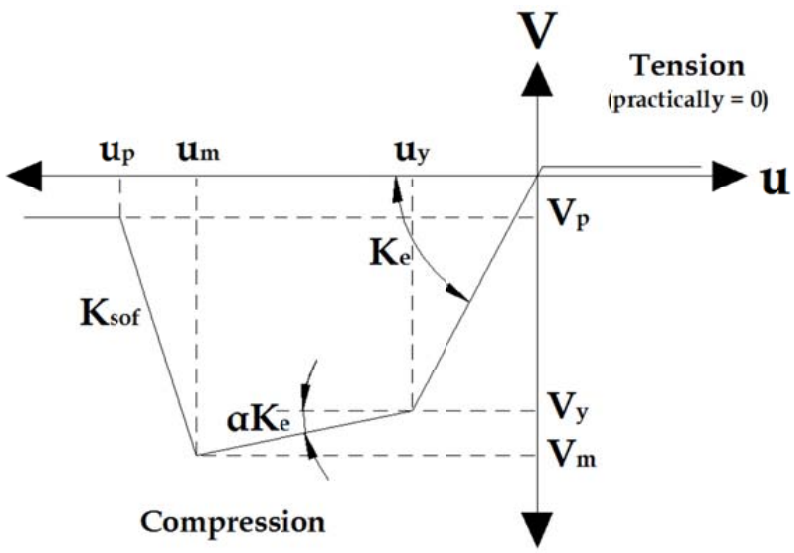

Fig. (3). Strength envelope for conventional masonry infill walls.

the length and the height of the infill. The maximum displacement $u_{m}$, corresponding to the maximum lateral force, is estimated according to Madan et al. [28] as follows:

$u_{m}=\frac{\varepsilon_{m}^{\prime} d_{i n}}{\cos \theta}$

where $\varepsilon_{m}$ is the maximum masonry compression strain taken equal to 0.0015 [27], $d_{\text {in }}$ is the diagonal strut length while $\theta$ is the inclination of the diagonal strut with respect to the horizontal axis. The initial stiffness $K_{e}$ can be estimated by:

$K_{e}=2\left(V_{m} / u_{m}\right)$

The lateral yielding force $V_{y}$, and the corresponding displacement $u_{y}$ are calculated from the envelope geometry:

$V_{y}=\frac{V_{m}-\alpha K_{e} u_{m}}{1-\alpha}$
$u_{y}=\frac{V_{y}}{K_{e}}$

The coefficient $\alpha$ is assumed to be equal to 0.2 , while the post-peak residual shear strength $V_{p}$ is considered as a function of the cracking shear [31]:

$V_{p}=\frac{1}{3} V_{y}$

The corresponding displacement value $u_{p}$ is calculated based on the assumption that the stiffness of the softening $K_{\text {sof }}$ branch is taken equal to $10 \%$ of the initial stiffness [25].

\section{MODELLING OF FUZZY PARAMETERS}

It is common in earthquake risk analysis to distinguish between uncertainty that reflects the variability of the outcome of a repeatable experiment and uncertainty due to ignorance. The first type of uncertainty is sometimes referred as "randomness", commonly known as "aleatory uncertainty", 
Table 1. List of the Natural Records

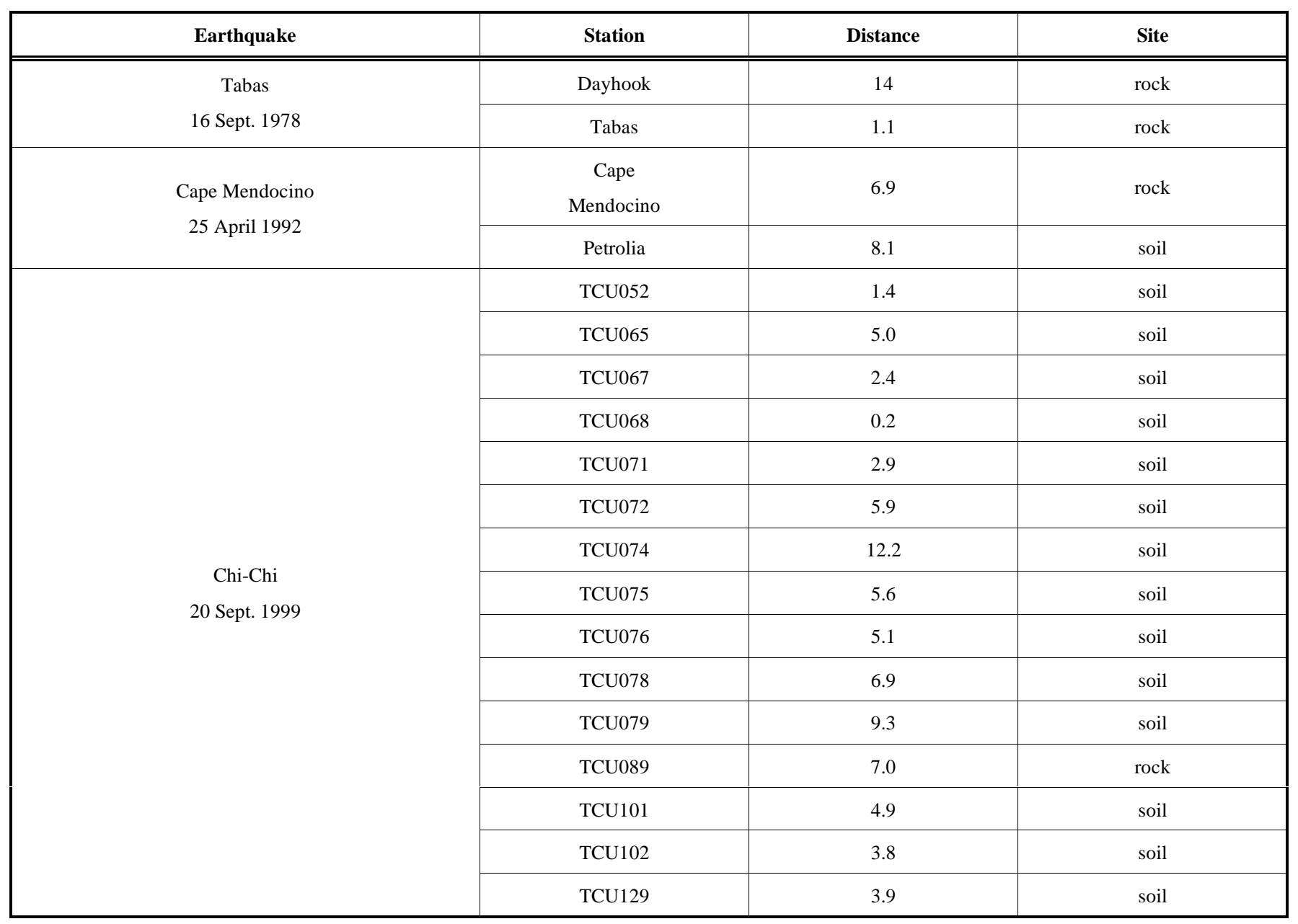

which cannot be reduced. However, both deterministic and probabilistic approaches are built on a number of model assumptions and model parameters that are based on what is currently known about the physics of the relevant processes and the behaviour of systems under given conditions. There is uncertainty associated with these conditions, which depends upon the state of knowledge that is referred as "epistemic uncertainty".

\subsection{Uncertain Parameters}

In this study various sources of uncertainty are considered: on the ground motion excitation (aleatory randomness) which influences the level of seismic demand and on the modelling (epistemic uncertainty) which affects the structural capacity. The structural stiffness is directly connected to the modulus of elasticity $E_{s}$ and $E_{c}$ of the steel and concrete respectively, while the strength is influenced by the yield stress $f_{y}$ of the steel and the cylindrical strength for the concrete $f_{c}$ and the hardening $b$ of the steel, while for the infill walls the cracking strength of the infill $f_{t p}$ andthe maximum masonry compression strain $\varepsilon_{m}^{\prime}$ are also considered as uncertain parameters. Thus, for the structural elements (col- umns and beams) three random variables are considered for the steel structure and two for the RCstructure; the modulus of elasticity $\left(E_{s}\right.$ and $E_{c}$ ), the yield and cylindrical strength stresses $\left(f_{\mathrm{y}}\right.$ and $\left.f_{c}\right)$ and the hardening parameter $b$ of the stress-strain curve and two for the diagonal compression struts $\left(f_{t p}\right.$ and $\left.\varepsilon_{m}^{\prime}\right)$.

The most common approach for the definition of the seismic input is the use of design code response spectrum. This is a general approach, which is easy to implement. However if higher precision is required the use of spectra derived from natural earthquake records is more appropriate. Since significant dispersion on the structural response due to the use of different natural records has been observed, these spectra must be scaled to the same desired earthquake intensity. The most commonly applied scaling procedure is based on the peak ground acceleration (PGA). In this study a set of nineteen natural accelerograms, shown in Table $\mathbf{1}$, is used. Each record corresponds to different earthquake magnitudes and soil properties. These time histories are from different earthquakes. Two are from the 1992 Cape Mendocino earthquake, two are from the 1978 Tabas, Iran earthquake and fifteen are from the 1999 Chi-Chi, Taiwan earthquake. The 


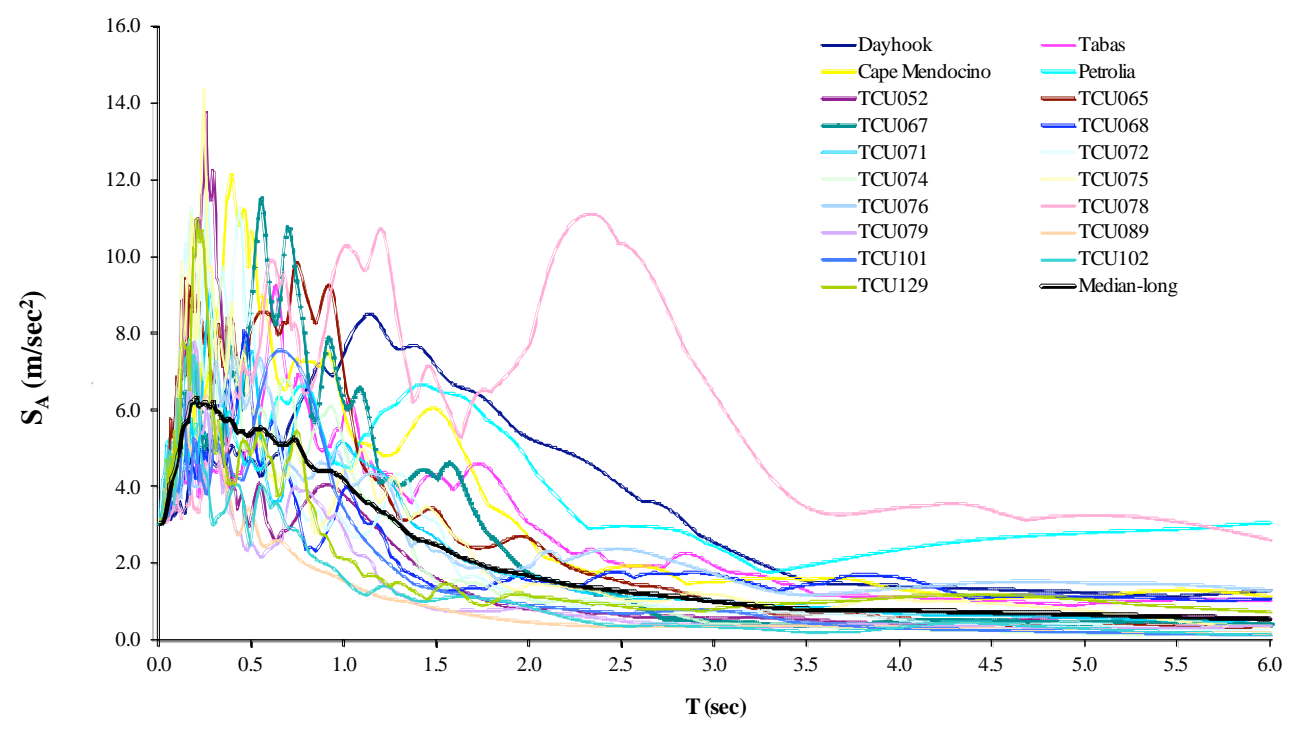

Fig. (4). Natural record response spectra and their median - longitudinal direction.

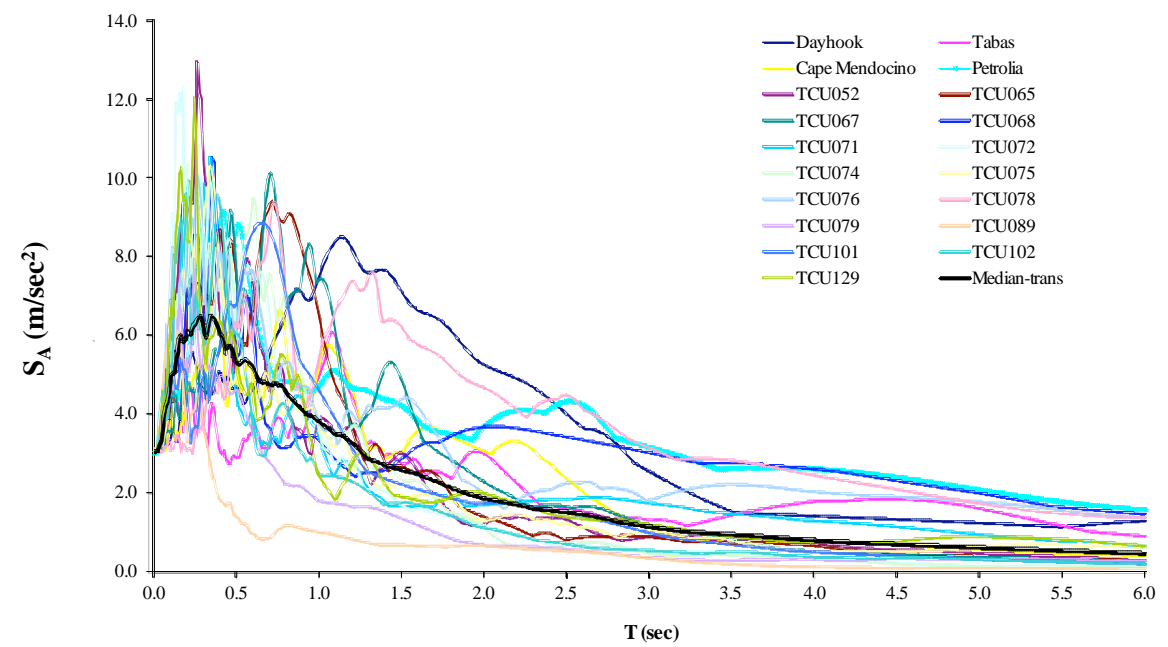

Fig. (5). Natural record response spectra and their median - transverse direction.

records are scaled, to the same peak ground acceleration of $0.31 \mathrm{~g}$ in order to ensure compatibility between them. The response spectra for each scaled record, in $\mathrm{x}$ and y directions, are shown in Figs. (4) and (5), respectively. It has been observed that the response spectra follow the lognormal distribution [32]. Therefore the median spectrum $\hat{\mathrm{x}}$, also shown in Figs. (4) and (5), and the standard deviation $\delta$ are calculated from the above set of spectra using the following expressions:

$$
\begin{aligned}
& \hat{\mathrm{x}}=\exp \left[\frac{\sum_{\mathrm{i}=1}^{\mathrm{n}} \ln \left(\mathrm{R}_{\mathrm{d}, \mathrm{i}}(\mathrm{T})\right)}{\mathrm{n}}\right] \\
& \delta=\left[\frac{\sum_{\mathrm{i}=1}^{\mathrm{n}}\left(\ln \left(\mathrm{R}_{\mathrm{d}, \mathrm{i}}(\mathrm{T})\right)-\ln (\hat{\mathrm{x}})\right)^{2}}{\mathrm{n}-1}\right]^{1 / 2}
\end{aligned}
$$

where $R_{d, i}(T)$ is the response spectrum value for period equal to $\mathrm{T}$ of the $\mathrm{i}^{\text {th }}$ record $(\mathrm{i}=1, \ldots, \mathrm{n}$, where $\mathrm{n}=19$ in this study).

\subsection{Fuzzification of Uncertain Parameters}

Fuzzification is understood to be the specification of the membership function $\mu(x)$ of an uncertain set andthe result of fuzzification is the fuzzy valuex. We assume that the numerical properties (the modulus of elasticity $E_{s}$ and $E_{c}$ of the steel and concrete respectively, the yield stress $f_{y}$ of the steel, the cylindrical strength for the concrete $f_{c}$, the hardening $b$ of the steel, thecracking strength of the infillandits maximum masonry compression strain)and the acceleration $\mathrm{R}_{\mathrm{d}}$ are uncertain and they are defined by means of triangular fuzzy variables. Since material properties and accelerationare uncertain parameters (fuzzy variables), maximum interstorey drift $\theta_{\max }$ is also a fuzzy variable. As an example, the membership function of $\theta_{\max }$ is depicted in Fig. (6). It is obtained 
Table 2. Basic Fuzzy Variables

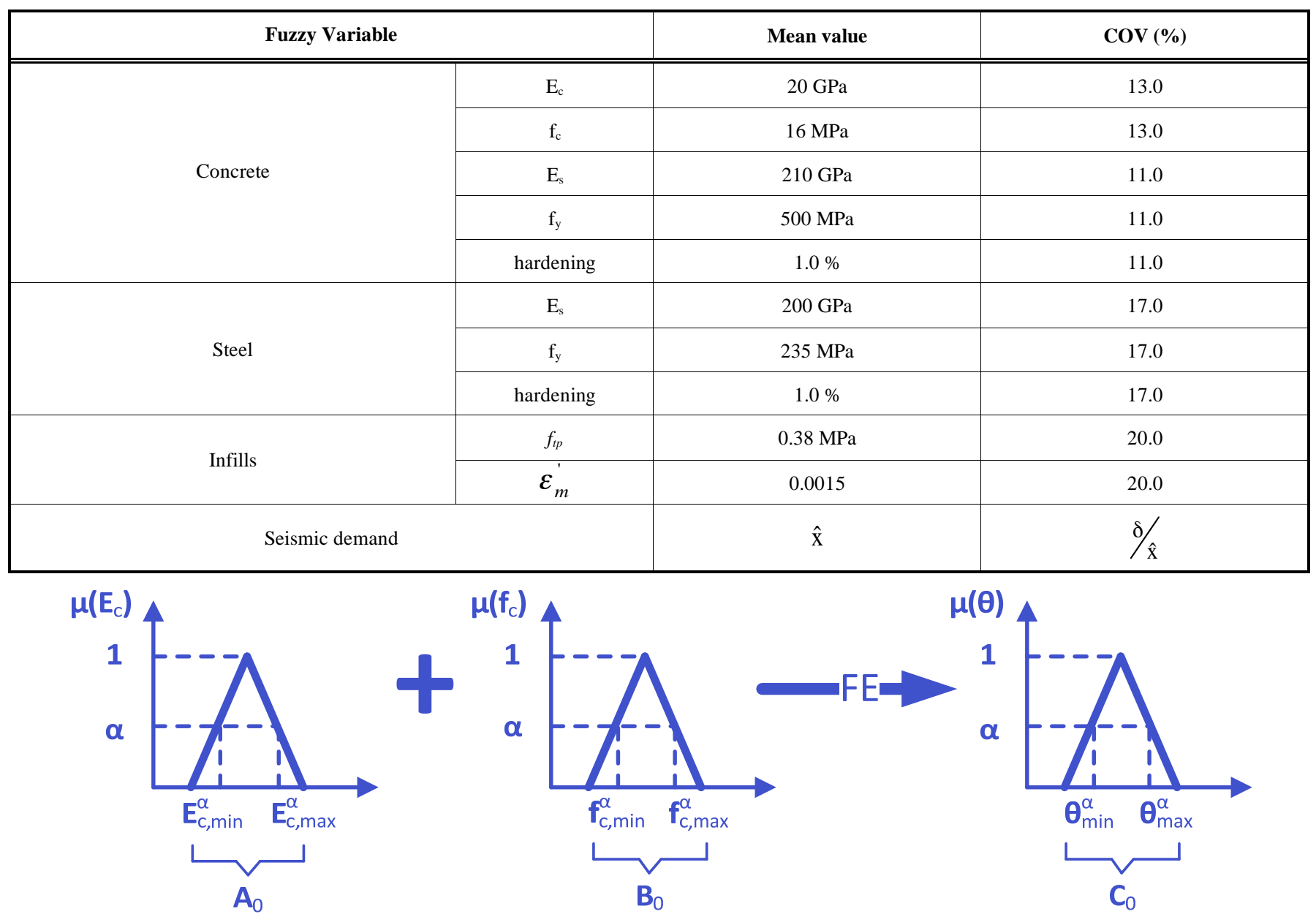

Fig. (6). $\alpha$-cut procedure for defining the membership function of the response.

assuming triangular fuzzy numbers $\mathbf{x}=\left[\mathbf{x}_{\min }, \mathbf{x}_{\text {mean }}, \mathbf{x}_{\max }\right]$ for the fuzzy numbers: the first and the third numbers represent the lower and upperbounds of support, and the middle number is thevalue whose membership function is equal to unity corresponding to the mean value of the uncertain parameter. The characteristics of the random variables based on the work by [33,34] are provided in Table 2 , where the mean value of the concrete compressive strength is $12 \%$ higher than its nominal value, the mean value of the yield stress for the steel reinforcement is $5 \%$ higher than its nominal value and that of the structural steel is $17 \%$ higher than its nominal value. The minimum and maximum values of the fuzzy numbers are defined by subtracting and adding the standard deviations to the mean value, therefore for the seismic demand, for a given period value, the acceleration $R_{d}$ is also obtained as a fuzzy number $\tilde{R}_{d}=[\hat{x}-\delta, \hat{x}, \hat{x}+\delta]$ whose mean value is equal to $\hat{x}$ and standard deviation is equal to $\delta$.

\section{3. $\alpha$-level Optimization}

Uncertain parameters are considered to be fuzzy numbers described with membership functions. Fig. (6) shows three fuzzy parameters, two inputs $\left(E_{c}\right.$ and $\left.f_{c}\right)$ and one output $(\theta)$ parameter, represented as triangular fuzzy numbers with support values of $A_{0}, B_{0}$ and $C_{0}$, respectively. The fuzzy set that contains all elements with a membership of $\alpha \in[0,1]$ and above is called the $\alpha$-cut of the membership function. At $\alpha$ level it will have support of $\mathrm{A}_{\alpha}$ defined by $\left[\mathrm{E}_{\mathrm{c}, \text { min }}^{\alpha}, \mathrm{E}_{\mathrm{c}, \max }^{\alpha}\right], \mathrm{B}_{\alpha}$ defined by $\left[\mathrm{f}_{c, \text { min }}^{\alpha}, \mathrm{f}_{\mathrm{c}, \max }^{\alpha}\right]$ and $\mathrm{C}_{\alpha}$ defined by $\left[\theta_{\text {min }}^{\alpha}, \theta_{\text {max }}^{\alpha}\right]$. According to this method,the membership function is cut horizontally at a finite number of $\alpha$-levels between 0 and 1 . For each $\alpha$-level of the parameter, the model is run to determine the minimum and maximum possible values of the output. This is achieved solving the following optimization problems for each level:

$$
\begin{aligned}
& \mathrm{z}=\mathrm{f}\left(\mathrm{x}_{1}, \ldots, \mathrm{x}_{\mathrm{n}}\right) \rightarrow \operatorname{Max} \mid\left(\mathrm{x}_{1}, \ldots, \mathrm{x}_{\mathrm{n}}\right) \in \mathbf{X}_{\alpha} \\
& \mathrm{z}=\mathrm{f}\left(\mathrm{x}_{1}, \ldots, \mathrm{x}_{\mathrm{n}}\right) \rightarrow \operatorname{Min} \mid\left(\mathrm{x}_{1}, \ldots, \mathrm{x}_{\mathrm{n}}\right) \in \mathbf{X}_{\alpha}
\end{aligned}
$$

where all fuzzy input values are cut horizontally using the same of $\alpha$-level. For each fuzzy input value $x_{i}$ on the level $\alpha$ the $\alpha$-level set $A_{i, a}$ is then defined and all $\alpha$-level sets form the subspace $\mathbf{X}_{a}$. With the aid of the mapping operator 


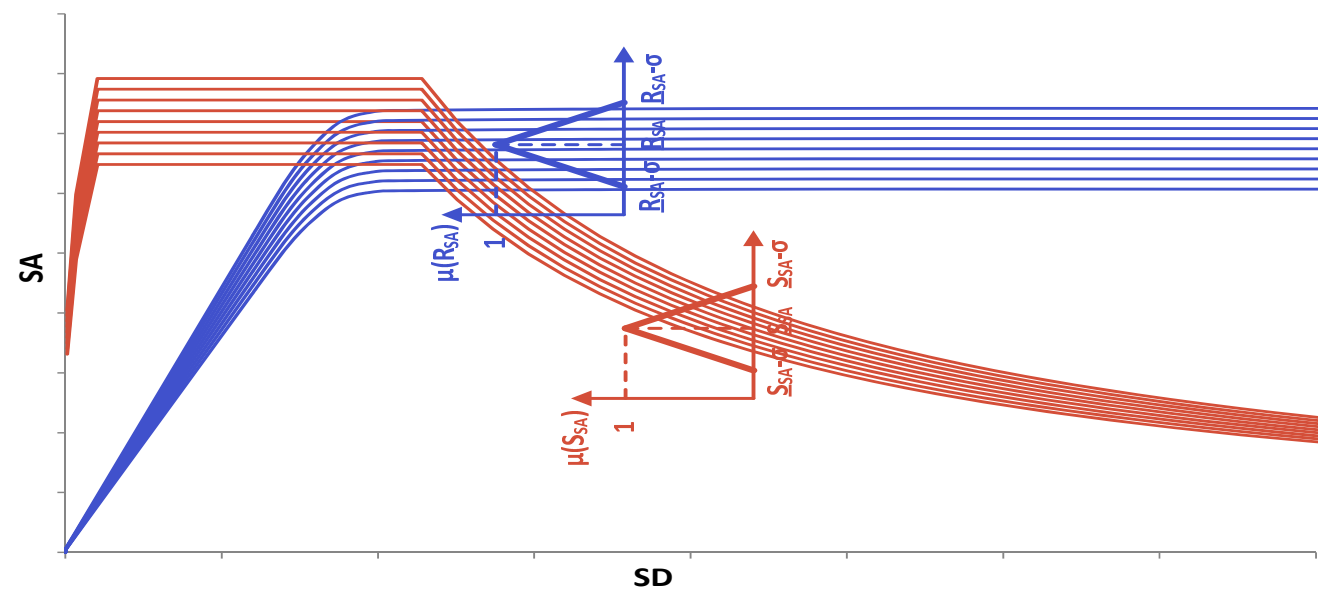

Fig. (7). Fuzzy capacity spectrum method.

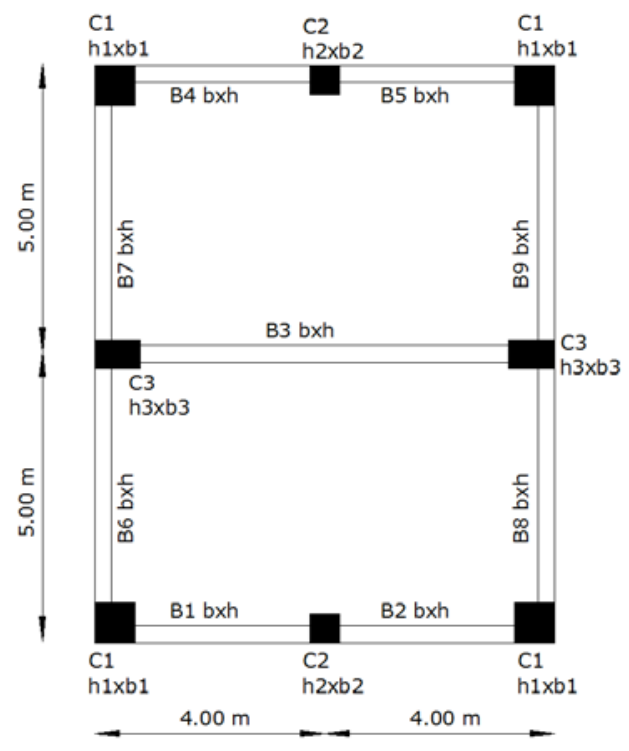

(a)

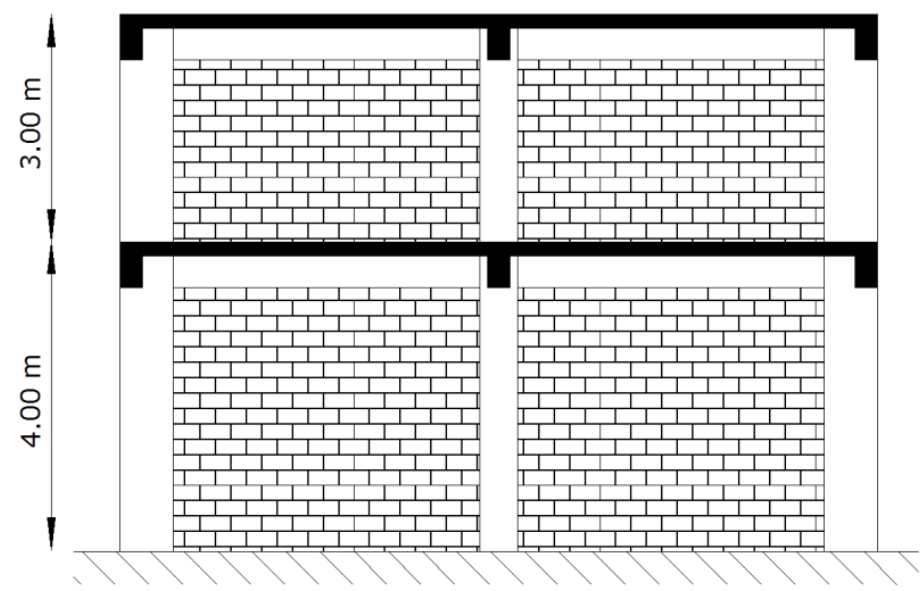

(b)

Fig. (8). RC structure-geometry of the two storey concrete structure (a) plan view and (b) side view

$\mathrm{z}=\mathrm{f}\left(\mathrm{x}_{1}, \ldots, \mathrm{x}_{\mathrm{n}}\right)$ it is possible to compute elements of the $\alpha$ levels sets $B_{a}$ of the fuzzy output values. This information is then directly used to construct the corresponding fuzziness (membership function) of the output ( $\theta$ in Fig. 6) which is used as a measure of uncertainty.Once the largest elementand the smallest element $\left[\mathrm{z}_{\min }^{\alpha}, \mathrm{z}_{\max }^{\alpha}\right]$ of the $\alpha$-levels sets $B_{a}$ have been found then two points of the membership function $\mu(z)$ are known (Fig. 6). If the output is monotonic with respect to the dependent fuzzy variables, the process is rather simple since only two simulations will be enough for each $\alpha$ level (one for each boundary). Otherwise, optimization routines have to be carried out to determine the minimum and maximum values of the output for each $\alpha$-level. In this study an evolutionary based optimization algorithm was implemented which was found to be very efficient in a number of studies $[35,36]$.

\section{FUZZY CAPACITY SPECTRUM METHOD}

The capacity spectrum method (CSM) was initially proposed by Freeman [37]. The method compares the capacity of a structure to resist lateral forces to the demand given by a response spectrum in a graphical manner. Theresponse spectrum represents the demand while the pushover curve (or the "capacity curve") represents the available capacity. Both curves are converted and plotted against an accelerationdisplacement graph (AD graph) making easy the evaluation of the point of equal demand and supply, also known as performance point. In this work a fuzzy capacity spectrum method (FCSM) is proposed. Since the material properties are fuzzy numbers multiple fuzzy capacity curves are obtained, while considering the response spectrumacceleration $\mathrm{R}_{\mathrm{d}}$ as a fuzzy number, multiplefuzzy response spectra are defined (see Fig. 7).Similar to the deterministic CSM in FCSM both groups of curves are converted and plotted against acceleration-displacement graphs(AD graphs) leading to multiple performance points which are also fuzzy numbers by combining each fuzzy capacity curve with one fuzzy representation of the response spectrum. The steps of the method are briefly summarized as follows: 


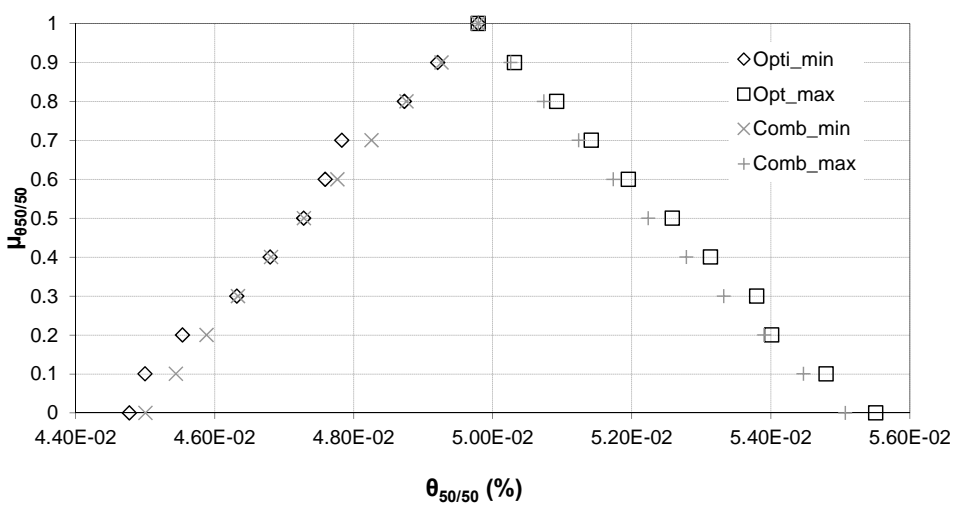

(a)

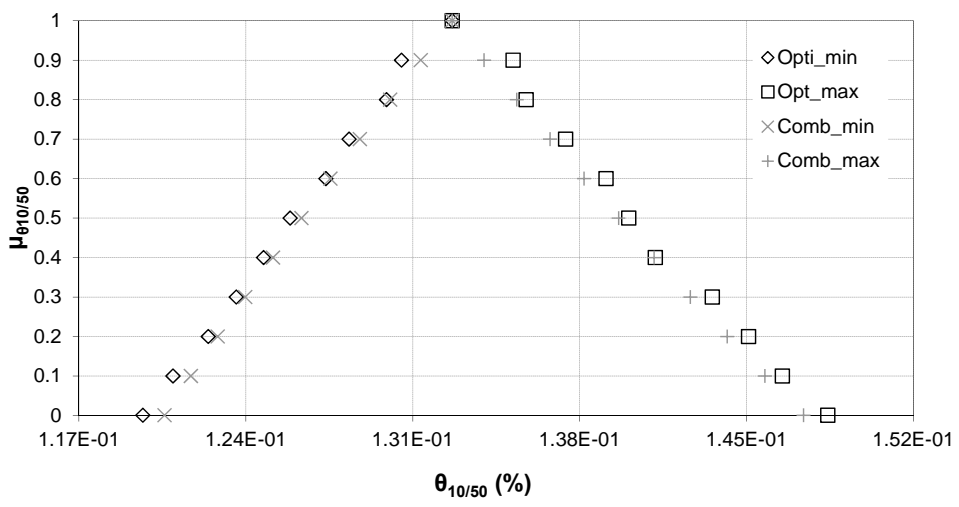

(b)

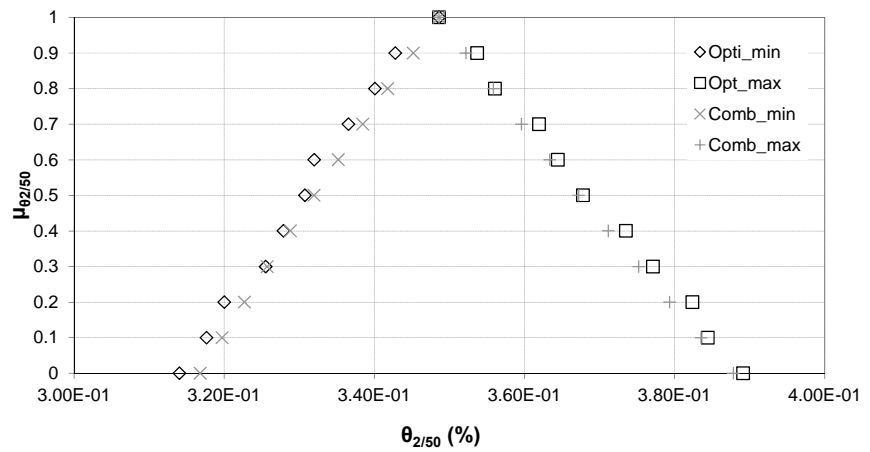

(c)

Fig. (9). RC structure-membership functions of the maximum interstorey drift for the (a) 50/50, (b) 10/50 and (c) 2/50 hazard levels

a) Perform pushover analysis and determine the capacity or pushover curve in base shear versus roof displacement $\left(V_{\mathrm{b}}-D\right)$ for various combinations of the fuzzy material properties.

b) Convert the pushover curves of the MDOFsystem to the capacity diagrams of equivalent SDOFsystemsusing the first mode participation factor $\Gamma$. Then approximate the capacity curves with an idealized elasto-perfectly plastic relationship.

c) Convert the idealized fuzzy capacity curves from $V_{\mathrm{b}}-D$ to AD terms. Plot the fuzzy capacity curves on the same graphs with the 5\%-damped fuzzy elastic response spectra that are also in $\mathrm{AD}$ format. For each combination of the fuzzy material properties (of step i) a fuzzy realization of the elastic response spectrum is generated.

d) Estimate the peak deformation demands $D$ and determine the corresponding pseudo-accelerations $A$ from the fuzzy capacity diagrams. Initially, assume $D=D\left(T_{\mathrm{e}}, \zeta=5 \%\right)$, determined for period $T_{e}$ from the elastic demand diagram.

e) Compute ductility $\mu=D / u_{\mathrm{y}}$ and calculate the hysteretic damping $\zeta_{\mathrm{h}}$ as $\zeta_{\mathrm{h}}=2(\mu-1) / \pi \mu$. The equivalent damping ratiosare evaluated from a relationship of the form for each combination of fuzzy capacity curve-fuzzy response spectrum:

$\mathfrak{x}_{e q}=\mathfrak{æ}_{e l}+\hat{\mathrm{e}} \mathfrak{h}_{h}$ 


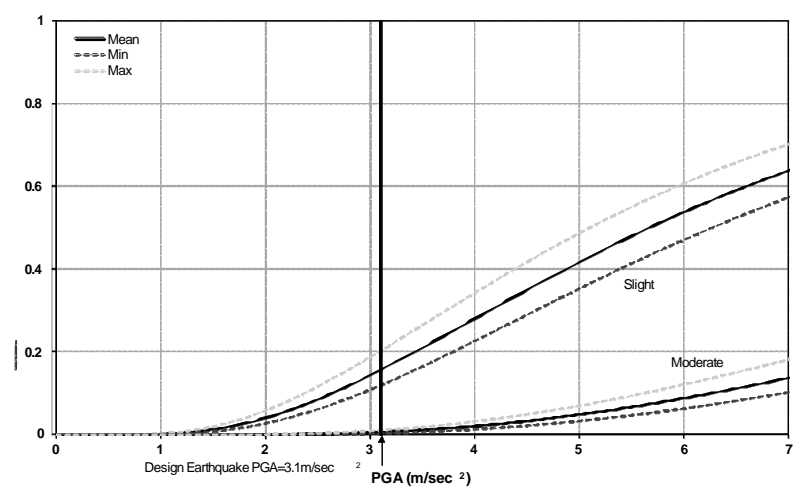

(a)

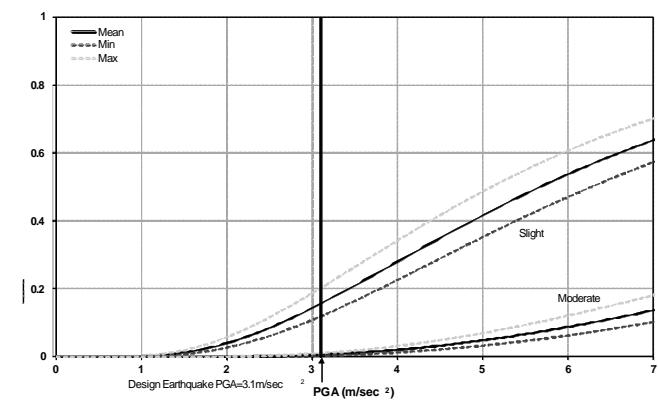

Fig. (10). RC structure-fuzzy fragility curves for the slight and moderate damage states.

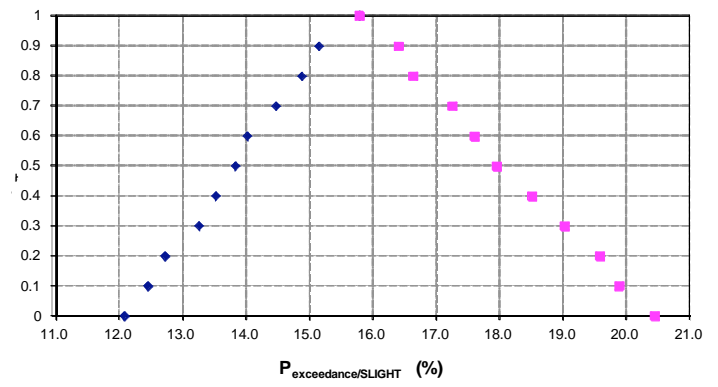

(a)

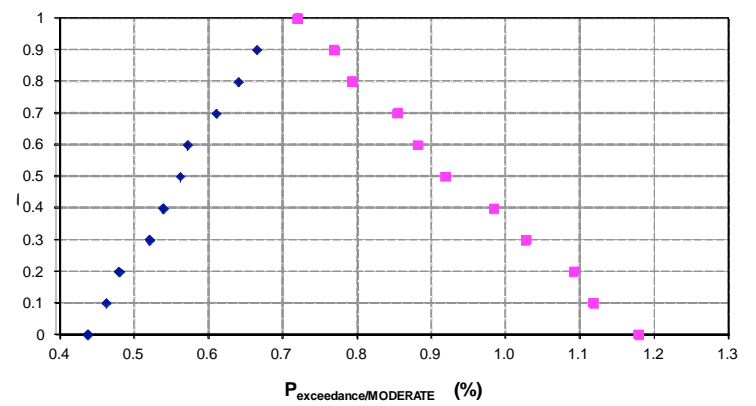

(b)

Fig. (11). RC structure-membership functions of the probability of exceedance for the (a) slight and (b) moderate damage states for the design earthquake

where $\kappa$ is a damping modification factor that depends on thehysteretic behavior of the system.

a) Plot the elastic demand diagram for $\zeta_{\text {eq }}$ and read of the displacement $D$, where this curve intersects the capacity diagram.

b) Check for convergence the displacement $D$. If the change in $D$ is sufficiently small the target displacement for the
SDOF system is $d_{t}^{*}=D$ and the corresponding displacement of the MDOF system is equal to $d_{t}=\tilde{A} d_{t}^{*}$. Otherwise go back to step $i$.

\section{NUMERICAL RESULTS}

Two test examples are considered for performing the parametric study described in this work. In particular one rein- 
Table 3. Mean, Mix and MIN Probabilities of Exceedance

\begin{tabular}{|l|c|c|c|}
\hline \multirow{2}{*}{\begin{tabular}{l} 
Limit state \\
\cline { 2 - 4 }
\end{tabular}} & Mean & Min & \multicolumn{2}{c|}{ Probability of exceeding the limit state (\%) } \\
\cline { 2 - 4 } Slight & 15.80 & 12.10 & 20.40 \\
\hline \hline Moderate & 0.72 & 0.44 & 1.18 \\
\hline
\end{tabular}

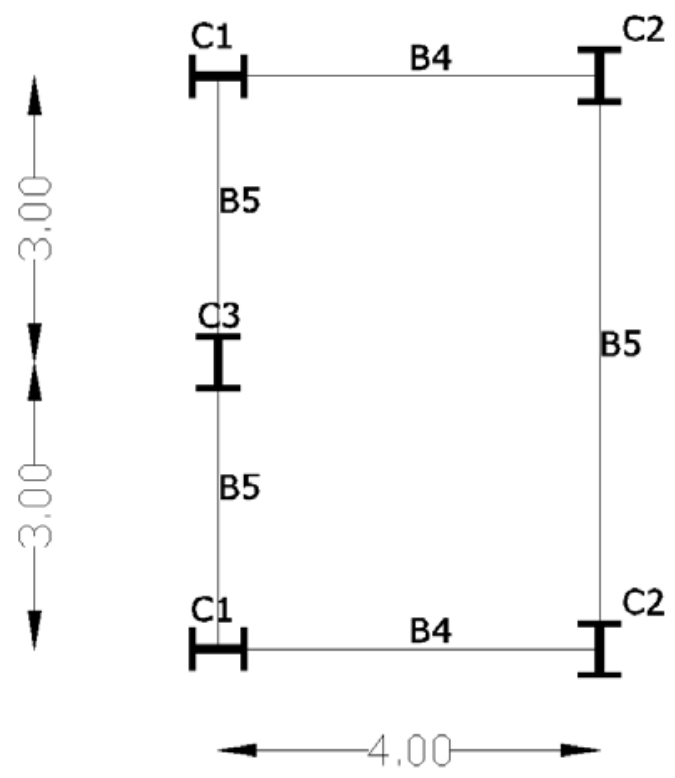

(a)

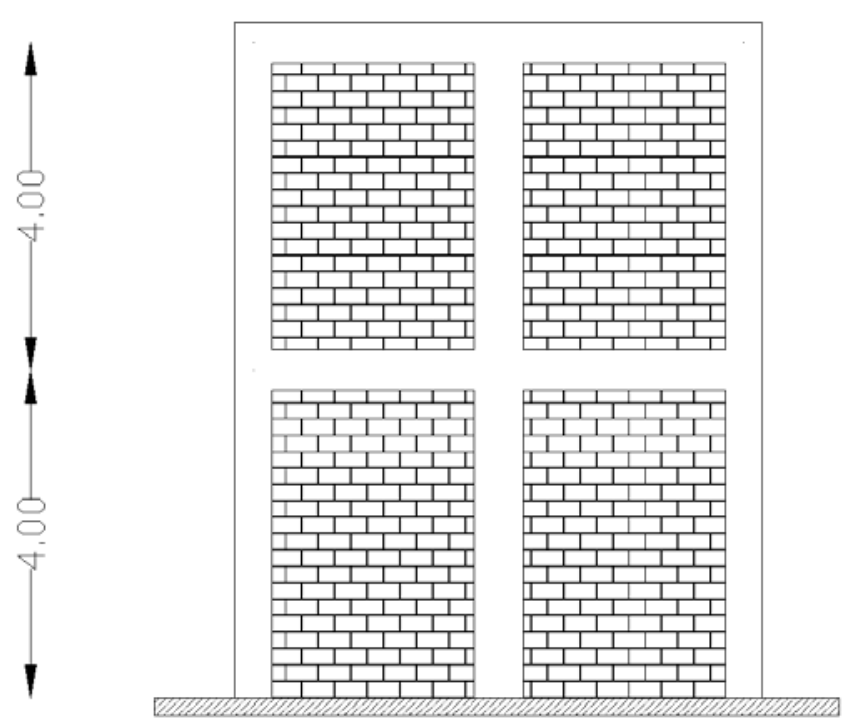

(b)

Fig. (12). Steel structure-geometry of the two storey steel structure (a) plan view and (b) side view.

forced concrete and one steel three dimensional framed structures are employed.For both test examples the lateral forces imposed by the EC8 [38] were derived from the design response spectrum (5\%-damped elastic spectrum divided by the behaviour factor $q=3.0$ for the reinforced concrete and $q=4.0$ for the steel test examples, respectively) at the fundamental period of the structure. The base shear is obtained from the response spectrum for soil type B (stiff soil $\theta=1.0$, with characteristic periods $\mathrm{T}_{1}=0.15 \mathrm{sec}$ and $\mathrm{T}_{2}=$ $0.60 \mathrm{sec}$ ) and a PGA of $0.31 \mathrm{~g}$. Moreover, the importance factor $\gamma_{\mathrm{I}}$ was taken equal to 1.0, while damping correction factor is equal to 1.0 , since a damping ratio of $5 \%$ has been considered.

\subsection{Concrete Test Example}

The two storey RC structure, shown in Fig. (8), has been considered in order to develop the fuzzy fragility curves. In the framework of this study, the RC building has been designed to meet the Eurocode (EC2 [39] and EC8 [38]) requirements. Concrete of class C16/20 (nominal cylindrical strength of 16MPawith modulus of elasticity equal to 30 GPa) and class B500steel (nominal yield stress of 500MPawith modulus of elasticity equal to $210 \mathrm{GPa}$ ) are assumed. Compared to the confined concrete the cylindrical strength of the unconfined concrete is reduced by $20 \%$. The slab thickness is equal to $18 \mathrm{~cm}$ and is considered to contrib- ute to the moment of inertia of the beams with an effective flange width. In addition to the self-weight of the beams and the slab, a distributed dead load of $2 \mathrm{kN} / \mathrm{m}^{2}$, due to floor finishing and partitions and imposed live load with nominal value of $1.5 \mathrm{kN} / \mathrm{m}^{2}$, is considered, in the combination with gravity loads ("persistent design situation"). Nominal dead and live loads are multiplied by load factors of 1.35 and 1.5, respectively. Following EC8, in the seismic design combination, dead loads are considered with their nominal value, while live loads with $30 \%$ of their nominal value. Moreover, the strong-column weak-beam guideline was followed in the design process. The dimension of all the columns is $60 \times 60$ $\mathrm{cm}^{2}$ with $16 \varnothing 20$ longitudinal reinforcement while the beams are $30 \times 60 \mathrm{~cm}^{2}$ with $8 \varnothing 18$ longitudinal reinforcement.

In the first part of this study the fuzzy nonlinear static analysis of this building is considered where the fuzzy response in terms of maximum interstorey drift in three hazard levels is defined. For this purpose the FCSM is implemented and the fuzziness of the maximum interstorey drift is definedusing both the minimum and maximum values of the fuzzy parameters (material properties and seismic demand) and solving the optimization problems described in Eqs. (12a) and (12b)considering 10 a-levels. The resultsarepresented in Figs. (9a) to (9c) where Comb_min and Comb_max represent the membership function of themaximum interstorey drift implementing theminimum and maximum values of 


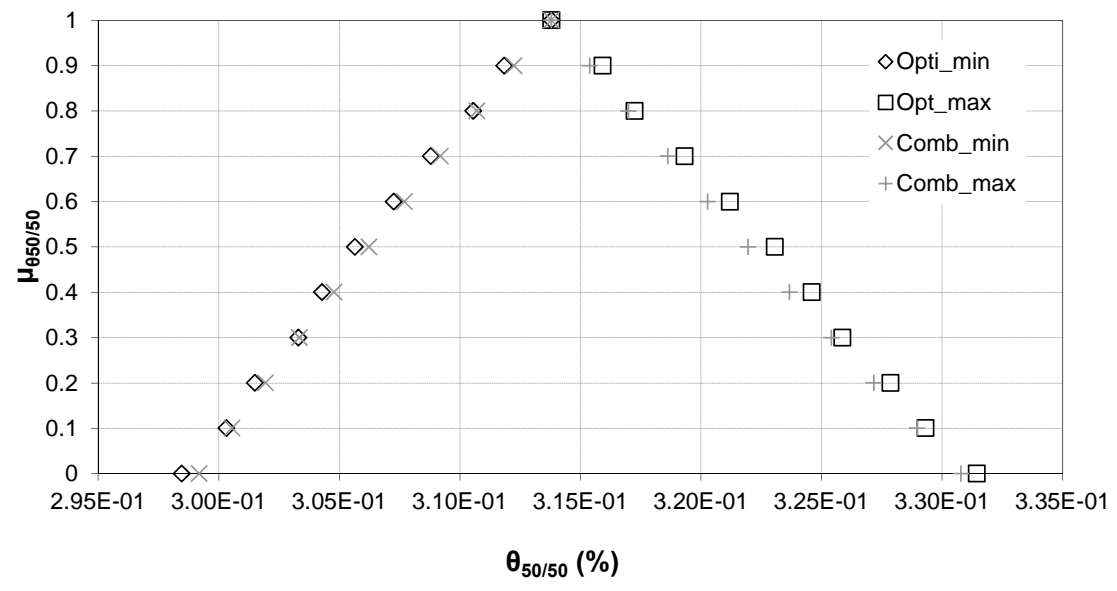

(a)

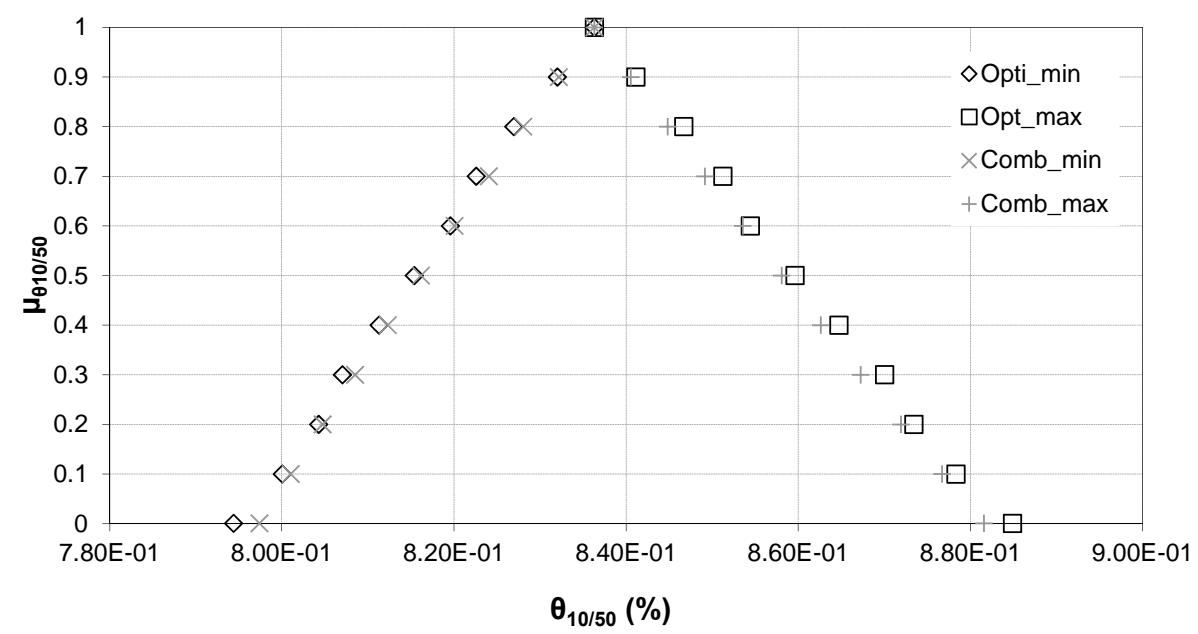

(b)

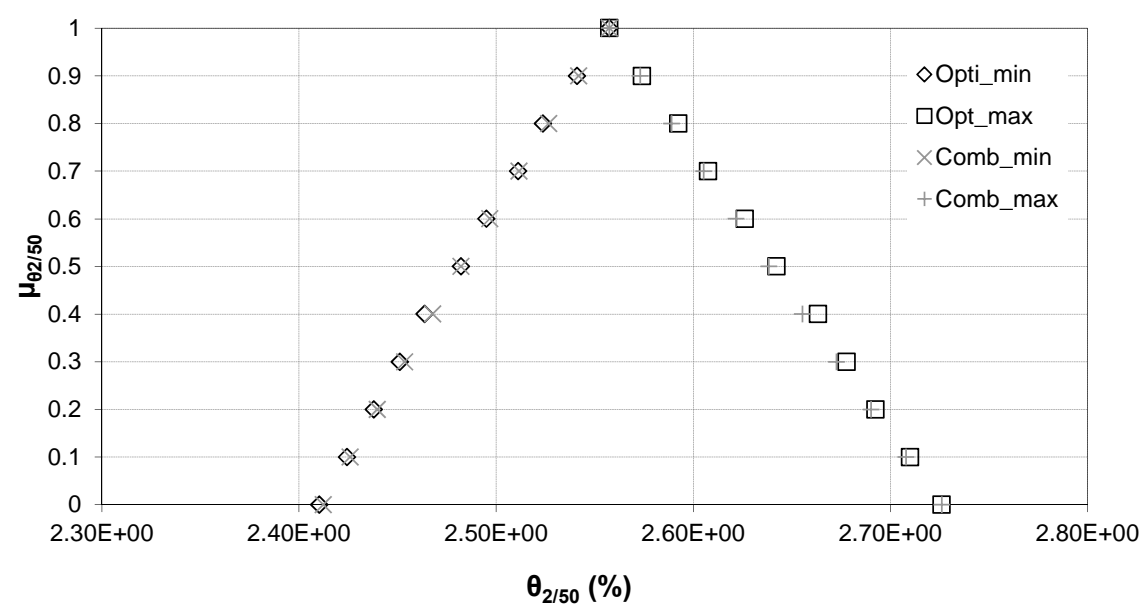

(c)

Fig. (13). Steel structure-membership functions of the maximum interstorey drift for the (a) 50/50, (b) 10/50 and (c) 2/50 hazard levels.

the fuzzy parameters (material properties and seismic demand), while Opti_min and Opti_max represent the membership function defined solving the problems described in Eqs. (12a) and (12b). As it can be seen the two membership func- tions are close defining a triangular membership function for all three hazard levels.

In the next step fragility analysis is performedbased on FCSM. Fig. (10) depicts the limit state fragility curves for 


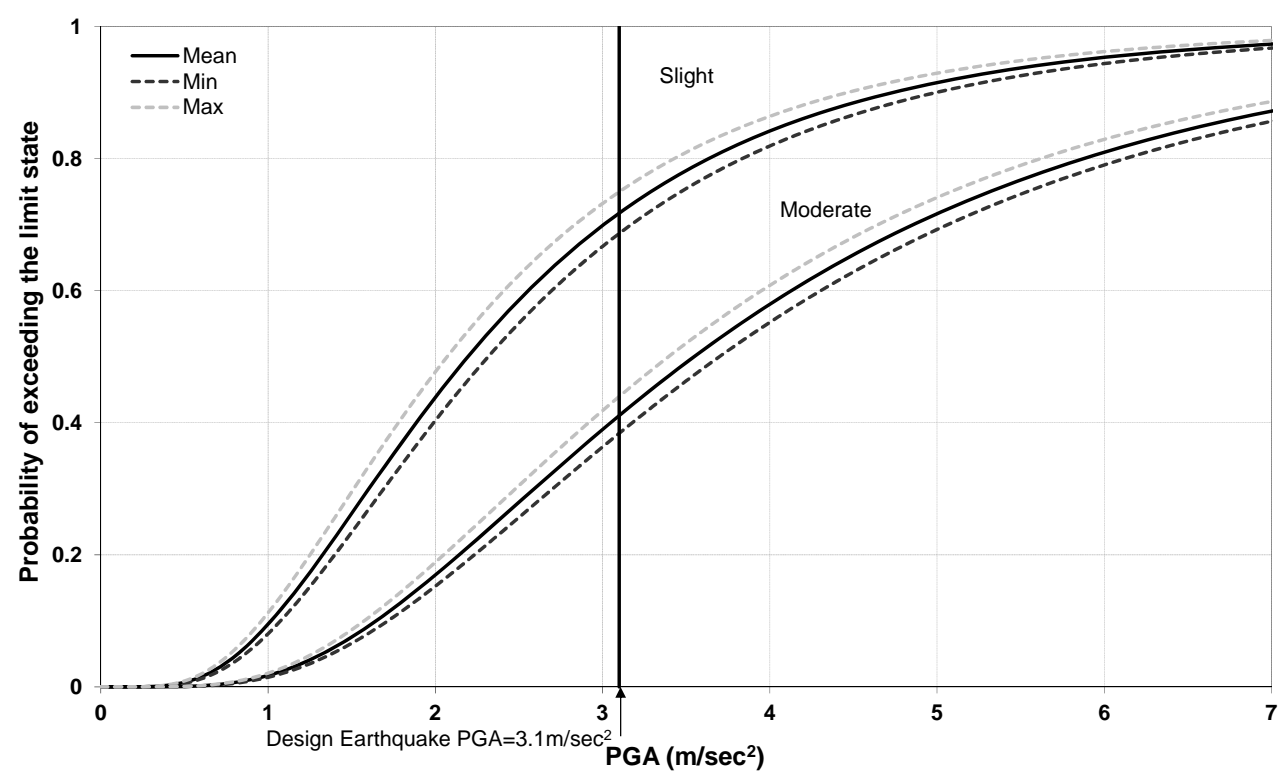

Fig. (14). Steel structure-fuzzy fragility curves for the slight and moderate damage states.

low-rise RC buildings for the high code design level as described by the earthquake loss estimation methodology (HAZUS) [40] for the slight and moderate structural damage states. The damage states, defined with respect to the drift limits according to HAZUS for this type of structure, are equal to $0.25 \%$ and $0.60 \%$ for slight and moderate structural damage states, respectively. Fig. (10) presents the triangular membership functions of the fragilities as defined with the minimum, maximum and mean fragility curves for the slight and moderate limit states. For the design earthquake $(\mathrm{PGA}=0.31 \mathrm{~g})$ theprobability of exceedance of the two limit states are considered as fuzzy variables and the membership functions are defined implementing theminimum and maximum values of the fuzzy parameters (material properties and seismic demand). These membership functions are shown in Figs. (11a) and (11b), while the mean, maximum and minimum values of the probability of exceedance are given in Table 3.

\subsection{Steel Test Example}

The two storey 3D steel structure, shown in Fig. (12), has been considered in order to perform the fuzzy based fragility analysis. In the framework of this study, the steel building has been designed to meet the Eurocode (EC3 [41] and EC8 [38]) requirements. Steel class S235 (nominal yield stress of 235 MPawith modulus of elasticity equal to $200 \mathrm{GPa}$ ) are assumed. The slab thickness is equal to $15 \mathrm{~cm}$ and is considered to contribute to the moment of inertia of the beams with an effective flange width. In addition to the self-weight of the beams and the slab, a distributed dead load of $2 \mathrm{kN} / \mathrm{m}^{2}$, due to floor finishing and partitions and imposed live load with nominal value of $1.5 \mathrm{kN} / \mathrm{m}^{2}$, is considered, in the combination with gravity loads ("persistent design situation"). Nominal dead and live loads are multiplied by load factors of 1.35 and 1.5, respectively. Following EC8, in the seismic design combination, dead loads are considered with their nominal value, while live loads with $30 \%$ of their nominal value. Moreover, the strong-column weak-beam guideline was followed in the design process. The dimension of all the columns is: HEB340 for $\mathrm{C} 1$, HEB360 for $\mathrm{C} 2$ and HEB320 for C3; while the dimensions of the beams: IPE200 for B4 and IPE200 for B5.

In accordance to the first test example in this part the fuzzy nonlinear static analysis of this building is considered where the fuzzy response in terms of maximum interstorey drift in three hazard levels is defined. For this purpose the FCSM is implemented and the fuzziness of the maximum interstorey drift is defined using both the minimum and maximum values of the fuzzy parameters (material properties and seismic demand) and solving the optimization problems described in Eqs. (12a) and (12b)considering 10 alevels. The resultsarepresented in Figs. (13a) to (c) where Comb_min and Comb_max represent the membership function of themaximum interstorey drift implementing theminimum and maximum values of the fuzzy parameters (material properties and seismic demand), while Opti_min and Opti_max represent the membership function defined solving the problems described in Eqs. (12a) and (12b). As it can be seen the two membership functions are close defining a triangular membership function for all three hazard levels.

In the next step fragility analysis is performedbased on FCSM. Fig. (14) depicts the limit state fragility curves for low-rise steel buildings for the high code design level as described by the earthquake loss estimation methodology (HAZUS) [40] for the slight and moderate structural damage states. The damage states, defined with respect to the drift limits according to HAZUS for this type of structure, are equal to $0.60 \%$ and $1.00 \%$ for slight and moderate structural damage states, respectively. In Fig. (14) presents the triangular membership functions of the fragilities as defined with the minimum, maximum and mean fragility curves for the slight and moderate limit states. For the design earthquake (PGA $=0.31 \mathrm{~g}$ ) theprobability of exceedance of the two limit states are considered as fuzzy variables and the membership functions are defined implementing theminimum and maxi- 

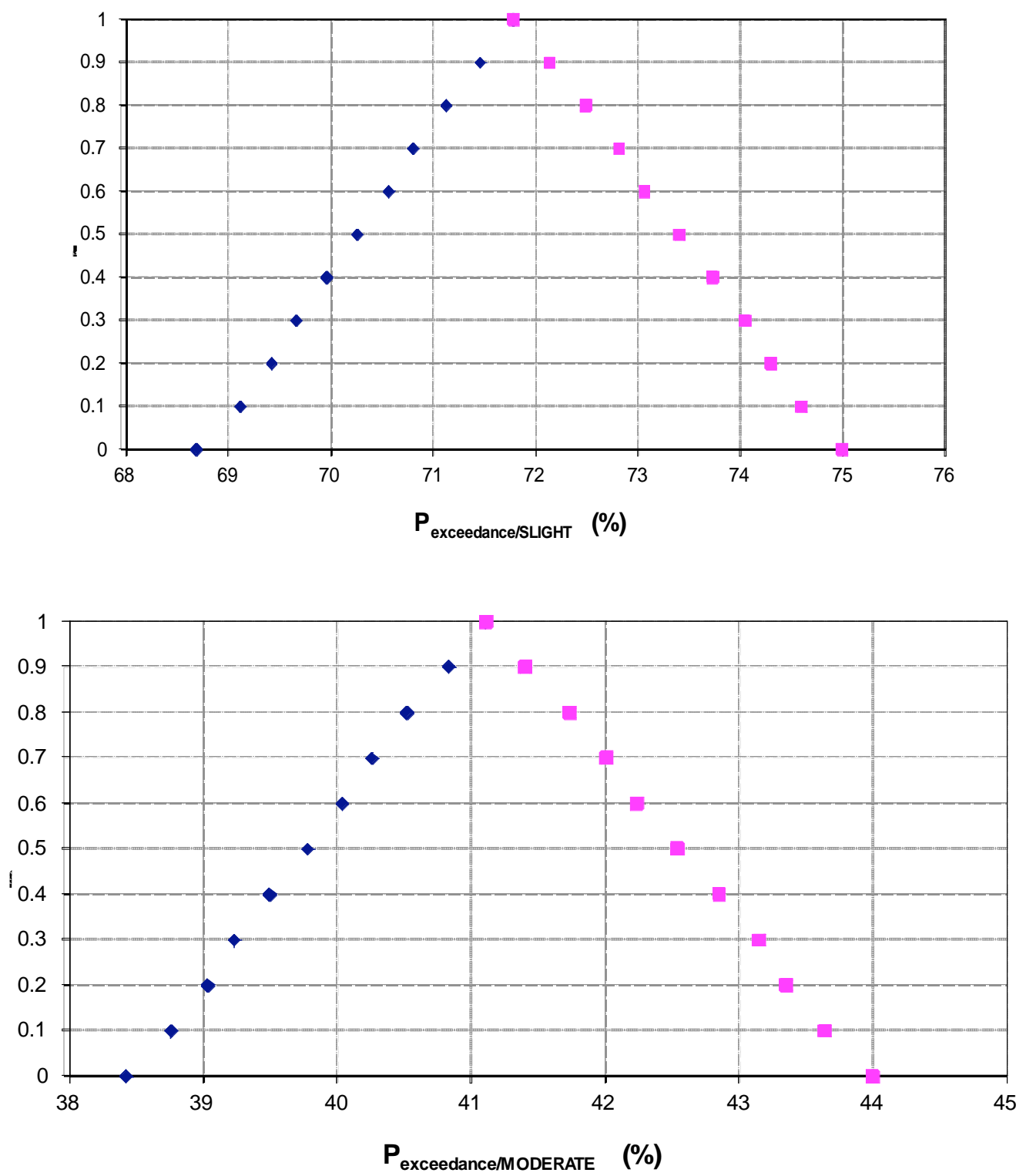

Fig. (15). Steel structure-membership functions of the probability of exceedance for the (a) slight and (b) moderate damage states for the design earthquake.

Table 4. Mean, Mix and Min Probabilities of Exceedance

\begin{tabular}{|l|c|c|c|}
\hline \multirow{2}{*}{ Limit state } & \multicolumn{3}{|c|}{ Probability of exceeding the limit state (\%) } \\
\cline { 2 - 4 } & Mean & Min & Max \\
\hline \hline Slight & 71.78 & 68.68 & 74.98 \\
\hline Moderate & 41.10 & 38.41 & 43.98 \\
\hline
\end{tabular}

mum values of the fuzzy parameters (material properties and seismic demand). These membership functions are shown in Figs. (15a) and (b), while the mean, maximum and minimum values of the probability of exceedance are given in Table 4 .

\section{CONCLUDING REMARKS}

In this work fragility curves associated with different limit-states of steel and reinforced concrete structures are developed, considering the influence of various sources of 
uncertainty.In particular randomness on the seismic demand and on the material propertiesis implemented considering fuzzy numbers with triangular membership functions. The fragility curves are defined by means of maximum drift values whileslight and moderate limit states are considered as defined for low-rise reinforced concrete and steel buildings for the high code design level as described by the earthquake loss estimation methodology of HAZUS. For this purpose onereinforced concrete and one steel 3D framed structureare considered. For the purposes of this study the fuzzy capacity spectrum method is proposed in order to define the fuzzy membership functions of both performance points and fragility curves. For the definition of the membership functionstwo procedures are implemented, using the minimum and maximum values of the fuzzy parameters (material properties and seismic demand) and solving the optimization problems defined with the $\alpha$-levels. It can be seen that both procedures provide similar results for the steel test example and with slight difference for the reinforced concrete test example.

\section{CONFLICT OF INTEREST}

The author confirm that this article content has no conflicts of interest.

\section{ACKNOWLEDGEMENT}

Declared none.

\section{REFERENCES}

[1] R.P. Kennedy, C.A. Cornell, R.D. Campbell, S. Kaplan, and H.F. Perla, "Probabilistic seismic safety study of an existing nuclear power plant", Nucl. Eng. Des., vol. 59, no. 2, pp. 315-338, 1980.

[2] C.A. Kircher, A.A. Nassar, O. Kustu, and W.T. Holmes, "Development of building damage functions for earthquake loss estimation", Earthquake Spectra, vol. 13, no. 4, pp. 663-682, 1997.

[3] Y.K. Wen, and B.R. Ellingwood, "The role of fragility assessment in consequence-based engineering", Earthquake Spectra, vol. 21, no. 3, pp. 861-877, 2005.

[4] K. Porter, R.P. Kennedy, and R. Bachman, "Creating fragility functions for performance-based earthquake engineering", Earthquake Spectra, vol. 23, no. 2, pp. 471-489, 2007.

[5] N.D. Lagaros, "Probabilistic fragility analysis of RC buildings designed with different rules", Earthquake Eng. Eng. Vibrat., vol. 7, no. 1, pp. 45-56, 2008.

[6] M. Shinozuka, M.Q. Feng, J. Lee, and T. Naganuma, "Statistical analysis of fragility curves", J. Eng. Mech., vol. 126, no. 12, pp. 1224-1231, 2000.

[7] H. Aslani, and E. Miranda, "Probability-based seismic response analysis", Eng. Struct., vol. 27, no. 8, pp. 1151-1163, 2005.

[8] O.C. Celik, and B.R. Ellingwood, "Seismic fragilities for nonductile reinforced concrete frames - Role of aleatoric and epistemic uncertainties", J. Struct. Safety, vol. 32, no. 1, pp. 1-12, 2012.

[9] J.H. Kim, I-K. Choi, and J-H. Park, "Uncertainty analysis of system fragility for seismic safety evaluation of NPP", Nucl. Eng. Des., vol. 241, no. 7, pp. 2570-2579, 2011.

[10] N.D. Lagaros, "Fragility assessment of steel and steel-concrete composite 3D buildings considering sources of uncertainty", Comput. Struct., 2011. (to appear).

[11] H. Kwakernaak, "Fuzzy random variables-I. Definitions and theorems", Info. Sci., vol. 15, pp. 1-29, 1978.

[12] M.L. Puri, and D. Ralescu, "Fuzzy random variables", J. Math. Anal. Appl., vol. 114, pp. 409-422, 1986.

[13] G. Wang, and Y. Zang, "The theory of fuzzy stochastic processes", Fuzzy Set Syst., vol. 51, pp. 161-178, 1992.

[14] I. Elishakoff, Eds. Whys and Hows in Uncertainty Modelling: Probability, Fuzziness and Anti-optimization. CISM Courses and Lectures. Springer Verlag: Wien, 1999.
[15] B. Möller, and M. Beer, Fuzzy Randomness: Uncertainty in Civil Engineering and Computational Mechanics. Springer-Verlag: Berlin, 2004.

[16] B. Ferracuti, M. Savoia, and I. Elishakoff, "Fuzzy safety factor", In: ICOSSAR 2005, Augusti G, Schuëller GI, Ciampoli M, Eds. MillPress: Rotterdam, 2005.

[17] J. Huo, and H.H.M. Hwang, "Incorporation of fuzzy damage states in seismic fragility analysis, Probabilistic Mechanics and Structural and Geotechnical Reliability", In: Proceedings of the Specialty Conference, 1996, p. 318.

[18] X. Gu, and Y. Lu, "A fuzzy-random analysis model for seismic performance of framed structures incorporating structural and nonstructural damage", Earthquake Eng. Struct., vol. 34, pp. 1305$1321,2005$.

[19] I. Elishakoff, and B. Ferracuti, "Fuzzy sets based interpretation of the safety factor", Fuzzy Set Syst., vol. 157, no. 18, pp. 2495-2512, 2006.

[20] M. Fragiadakis, and M. Papadrakakis, "Modelling, analysis and reliability of seismically excited structures: Computational issues", Int. J. Comput. Methods, vol. 5, no. 4, pp. 483-511, 2008.

[21] F. McKenna, and G.L. Fenves, The Open Sees Command Language Manual-Version 1.2. Pacific Earthquake Engineering Research Centre, University of California, Berkeley, 2001.

[22] D.C. Kent, and R. Park, "Flexural members with confined concrete", J. Struct. Div., vol. 97, no. 7, pp. 1969-1990, 1971.

[23] B.D. Scott, R. Park, and M.J.N. Priestley, "Stress-strain behaviour of concrete confined by overlapping hoops at low and high strain rates", ACI Struct. J., vol. 79, pp. 13-27, 1982.

[24] M. Menegotto, and P.E. Pinto, "Method of analysis for cyclically loaded reinforced concrete plane frames including changes in geometry and non-elastic behaviour of elements under combined normal force and bending", In: Proceedings, IABSE Symposium on Resistance and Ultimate Deformability of Structures Acted on by Well Defined Repeated Loads, 1973, pp. 15-22.

[25] G.M. Calvi, G. Via, and E. Vintzileou, "Reinforced concrete infilled frames", In: RC frames under earthquake loading, CEB Bulletin 231, Thomas Telford, pp. 231-284, 1996.

[26] A. Saneinejad, and B. Hobbs, "Inelastic design of infilled frames", J. Struct. Eng., vol. 121, no. 4, pp. 634-650, 1995.

[27] A. Madan, M. Reinhorn, J.B. Mander, and R.E. Valles, "Modelling of masonry infill panels for structural analysis", J. Struct. Eng., vol. 123, no. 10, pp. 1295-1302, 1997.

[28] P.G. Asteris, S.T. Antoniou, D.S. Sophianopoulos, C.Z Chrysostomou, "Mathematical macromodelling of infilled frames: state of the art", J. Struct. Eng., vol. 137, no. 12, pp. 1508-1517, 2011.

[29] M. Dols ek, and P. Fajfar, "Mathematical modelling of an infilled $\mathrm{RC}$ frame structure based on the results of pseudo-dynamic tests", Earthquake Eng. Struct., vol. 31, pp. 1215-1230, 2002.

[30] R. Žarnić, and S. Gostič, Masonry infilled frames as an effective structural sub-assemblage. Seismic Design Methodologies for the Next Generation of Codes, Fajfar P, Krawinkler H, Eds. Balkema: Rotterdam, pp. 335-346, 1997.

[31] Repapis, C. Zeris, and E. Vintzileou, "Evaluation of the seismic performance of existing RC buildings: I. Suggested methodology", J. Earthquake Eng., vol. 10, no. 2, pp. 265-287, 2006.

[32] Chintanapakdee, and A.K. Chopra, "Evaluation of modal pushover analysis using generic frames", Earthquake Eng. Struct., vol. 32, pp. 417-442, 2003.

[33] B.R. Ellingwood, T.V. Galambos, J.G. MacGregor, and C.A. Cornell, Development of a Probability-Based Load Criterion for American National Standard A58. National Bureau of Standards: Washington, DC, 1980.

[34] B.R. Ellingwood, and T.V. Galambos, "Probability-based criteria for structural design", Struct. Safety, vol. 1, no. 1, pp. 15-26, 1982.

[35] M. Papadrakakis, N.D. Lagaros, and Y. Fragakis, "Parallel computational strategies for structural optimization", Int. J. Numer. Methods Eng., vol. 58, no. 9, pp. 1347-1380, 2003.

[36] N.D. Lagaros, and V. Papadopoulos, "Optimum design of shell structures with random geometric, material and thickness imperfections", Int. J. Solids Struct., vol. 43, no. 22-23, pp. 6948-6964, 2006.

[37] S.A Freeman, Development and use of capacity spectrum method. Proc.6 US National Conference on Earthquake Engineering, 1998. 
[38] Eurocode 8, Design of Structures for Earthquake Resistance. European Committee for Standardisation: Brussels, Belgium, The European Standard EN 1998-1, 2004.

[39] Eurocode 2, Design of Concrete Structures-Part 1: General Rules and Rules for Buildings. European Committee for Standardisation: Brussels, Belgium, The European Standard EN 1992-1-1, 2004.
[40] FEMA-National Institute of Building Sciences. HAZUS-MH MR1, Multi-hazard Loss Estimation Methodology Earthquake Model, Washington, DC, 2003.

[41] Eurocode 3, Design of steel structures - Part 1: Crane Supporting Structures, European Committee for Standardisation: Brussels, Belgium, The European Standard, ENV 1993-1, 2005.

(C) Nikos D. Lagaros; Licensee Bentham Open.

This is an open access article licensed under the terms of the Creative Commons Attribution Non-Commercial License (http://creativecommons.org/licenses/by-nc/3.0/) which permits unrestricted, non-commercial use, distribution and reproduction in any medium, provided the work is properly cited. 